Relations industrielles

Industrial Relations

\title{
Les travailleurs frontaliers des régions wallonnes, par Louis Bouvir, Conseil économique wallon, Liège, 1967, 300 pages.
}

\section{Marc-André Dionne}

Volume 23, numéro 3, 1968

URI : https://id.erudit.org/iderudit/027942ar

DOI : https://doi.org/10.7202/027942ar

Aller au sommaire du numéro

Éditeur(s)

Département des relations industrielles de l'Université Laval

ISSN

0034-379X (imprimé)

1703-8138 (numérique)

Découvrir la revue

Citer ce compte rendu

Dionne, M.-A. (1968). Compte rendu de [Les travailleurs frontaliers des régions wallonnes, par Louis Bouvir, Conseil économique wallon, Liège, 1967, 300 pages.] Relations industrielles / Industrial Relations, 23(3), 522-522.

https://doi.org/10.7202/027942ar

Tous droits réservés ( Département des relations industrielles de l'Université Laval, 1968
Ce document est protégé par la loi sur le droit d'auteur. L'utilisation des services d'Érudit (y compris la reproduction) est assujettie à sa politique d'utilisation que vous pouvez consulter en ligne.

https://apropos.erudit.org/fr/usagers/politique-dutilisation/ 
flits collectifs du travail, Vogel-Poslky décrit les structures juridiques et le cadre institutionnel des rapports collectifs du travail en Belgique.

Dans la deuxième partie de l'ouvrage, I'auteur étudie les conflits collectifs de travail ou niveau de la profession dans dix secteurs industriels. Vogel-Polsky fait un examen des organismes officiels de conciliation institués ou sein des commissions paritaires nationales dans les dix secteurs étudiés. L'auteur fait de même pour la conciliotion officieuse dans les dix secteurs considérés par l'étude.

$\mathrm{Si}$ les préoccupations du lecteur sont d'ordre juridique, il trouvera dans I'analyse des institutions et des procédures mises en place pour résoudre les conflits collectifs du travail matière ò réflexion et à comparaison. Si par contre, il cherche une tentative d'explication sociologique des phénomènes observés, il sera certainement déçu.

\section{Marc-André DIONNE}

Les travailleurs frontaliers des régions wallonnes, par Louis Bouvir, Conseil économique wallon, Liège, 1967, 300 pages.
Lo Belgique est en contoct ovec quatre Etats; I'absence d'obstacles naturels entre elle et eux a favorisé depuis toujours les échanges de toute nature et les relations de voisinage. Cette situation a engendré le travail frontalier qui peut être défini comme suit: le fait que des résidents d'un pays traversent journellement lo frontière pour se rendre à leurs occupations.

La première partie de l'étude retrace l'évolution du travail frontalier et de son statut. L'auteur fait I'historique de ces mouvements, il fournit des statistiques régionales détaillées et enfin précise le statut international de ce type de travailleurs. Sur ce dernier point, Louis Bauvin traite de l'accès au marché du travail étranger, des problèmes monétaires que pose le travail frontalier, de la sécurité sociale et du régime fiscal de ces derniers.

La seconde partie de l'ourrage nous livre les résultats d'une enquête menée auprès de travailleurs frontaliers, principalement dans le but d'avoir une information plus complète sur les aspects qualitatifs du travail frontalier d'aujourd'hui.

\section{Marc-André DIONNE}

\section{PUBLICATIONS RECENTES}

\section{GENERALITES}

《La démocratisation de la formation», par Jacques Vande Graaf, Les Dossiers, $45 \mathrm{e}$ année, mars-avril 1968, no 3, pp. 218-221.

«Women in the Labor Force 》, by Margaret S. Gordon, Industrial Relations, vol. 7, No. 3, May 1968, pp. 187-193.

\&aycheck and Apron - Revolution in Womanpower $\gg$, by Eli Binzberg, Industrial Relations, Vol. 7, No. 3, May 1968, pp. 193 204.

« Patterns of Female Labor Force Activity », by Gertrude Bancroft McNally, Industrial Relations, Vol. 7, No. 3, May 1968, pp. 204219
"The Sex-Labeling of Jobs», by Valerie Kincade Oppenheimer, Industrial Relations, Vol. 7, No. 3, May 1968, pp. 219-235.

«Women's Work: Economic Growth, Ideology, Structure », by Harold L. Wilenski, Industrial Relations, Vol. 7, No. 3, May 1968, pp. 235249.

\& The Grocery Clerks: Center of Retail Unionism », by Marten Estey, Industrial Relations, Vol. 7, No. 3, May 1958, pp. 249. 262.

«Human Relations - 1968 Style », by George Strauss, Industrial Relations, Vol. 7, No. 3, pp. 262-276. 